\title{
A produção de grãos transgênicos: solução ou ameaça
}

\author{
The production of transgenic grains: solution or threat \\ La producción de granos transgénicos: solución ou amenaza
}

\author{
Maria Lúcia Giozza Hernandes ${ }^{1}$ \\ Clarice Borba dos Santos ${ }^{2}$
}

\begin{abstract}
Resumo
O artigo faz o relato de uma experiência pedagógica com uma turma de alunos do oitavo ano da E.M.E.F.Silvina Gonçalves. Trata-se de uma análise quanto ao uso da transgenia (produtos transgênicos ou organismos geneticamente modificados) na agricultura brasileira e, destacando-se a utilização desta, na atividade agrícola do município de Arroio Grande. Analisando-se, tanto as vantagens, como as desvantagens: riscos à saúde e a biodiversidade; problemas ambientais e socioeconômicos que agregam a essa biotecnologia agrícola, fundamentando-se em Karl Marx e suas teorias sobre a sociedade, economia e política aplicadas a agricultura num sistema capitalista
\end{abstract}

Palavras-chave: Transgenia. Biotecnologia agrícola.

\begin{abstract}
The article reports a pedagogical experience with a group of eighth grade students from E.M.E.F.Silvina Gonçalves. It is an analysis about the use of transgenic (transgenic products or genetically modified organisms) in Brazilian agriculture and, especially the use of this, in the agricultural activity of the municipality of Arroio Grande. Analyzing both the advantages and the disadvantages: health risks and biodiversity; environmental and socio-economic problems that add to this agricultural biotechnology, based on Karl Marx and his theories on society, economics and politics applied to agriculture in a capitalist system
\end{abstract}

Keywords: Transgenia. Agricultural Biotechnology.

\section{Resumen}

El artículo hace el relato de una experiencia pedagógica con una clase de alumnos del octavo año de la E.M.E.F.Silvina Gonçalves. Se trata de un análisis en cuanto al uso de la transgenia (productos transgénicos o organismos genéticamente modificados) en la agricultura brasileña y, destacándose la utilización de ésta, en la actividad agrícola del municipio de Arroio Grande. Analizando tanto las ventajas, como las desventajas: riesgos para la salud y la biodiversidad; problemas ambientales y socioeconómicos que agregan a esa biotecnología agrícola, fundamentándose en Karl Marx y sus teorías sobre la sociedad, la economía y la política aplicadas a la agricultura en un sistema capitalista.

Palabras-clave: Transgenia. Biotecnología Agrícola

\section{Introdução}

\footnotetext{
1 Mestra em Educação, Universidade Federal do Pampa, UNIPAMPA, Bagé, Rio Grande do Sul. E-mail: mariagiozza@bol.com.br

${ }^{2}$ Mestra em Educação, Universidade Federal do Pampa, UNIPAMPA, Bagé, Rio Grande do Sul. E-mail: claricebs@gmail.com
} 
Atualmente, há um grande avanço tecnológico mundial na agricultura e a necessidade de desenvolver novas técnicas de plantio para a produção em larga escala e o melhoramento de produtos, surgindo assim a biotecnologia como uma alternativa para os agricultores.

A biotecnologia consiste na modificação genética de organismos, plantas, animais e alguns vírus para a produção de materiais e substâncias a partir de seres vivos. No caso das plantas trangênicas, são utilizados dois métodos de transformação: 1- o que usa a bactéria Agrobacterium tumefaciens (método indireto, como o de uma infecção) e 2 - o que usa a biobalística (método direto, aleatório, sem controle, de introdução de gene na estrutura do DNA da planta). Nesses processos, não existe garantia comprovada de seus resultados, o que nos possibilita questionamentos quanto à biossegurança.

As plantas transgênicas, no que se refere a biossegurança na utilização e na sua produção, provocam enormes discussões. Nesse contexto, este artigo traz um relato de experiência pedagógica realizada na E.M.E.F.SILVINA GONÇALVES, no município de Arroio Grande, com uma turma de oitavo ano, abordando a produção de grãos transgênicos, sendo esta uma solução para a agricultura ou uma ameaça para a biodiversidade e saúde humana?

A primeira parte do artigo, tratará da busca de informações sobre transgênicos, vantagens e desvantagens da utilização destes. Os alunos através de vídeos, explanação oral, livros, revistas e artigos científicos se apropriaram de conhecimentos relevantes sobre as plantas transgênicas. Na segunda parte, será feita apresentação de relatos dos alunos, expondo a sua realidade e o consumo de produtos transgênicos, tanto na produção agrícola, como na alimentação diária, fazendo uma reflexão dos impactos destes à saúde humana.

O relato de experiência fundamentou-se em uma pesquisa bibliográfica com objetivo de analisar o uso da transgenia na agricultura do município de Arroio Grande

\section{Cultivo de Transgênicos e a interação homem x natureza}

Observa-se uma crescente expansão dos transgênicos no Brasil e consequentemente uma nova atividade dominanten nas relações com a natureza. Nesse sentido, destaca-se a reflexão marxista sobre as condições da produção de bens.

Marx (1998, p.238) identifica três condições para a produção de bens: 1) a condição pessoal, representada pela força de trabalho humano (capital humano); 2) a condição externa, que serve como base material da produção - os recursos naturais, a terra (capital ambiental); 
e, por fim, 3) as condições gerais representada pela infraestrutura - meios de comunicação e de transporte.

Desta forma, às interações entre o homem e a natureza no quadro da produção de bens, Andrioli (2014) defende que “ a interação entre o ser humano e a natureza é definida pelas relações de produção vigentes na sociedade.”

Isto quer dizer que tanto o trabalho quanto a terra são transformados em bens; portanto, estão sujeitos às leis do mercado, o que significa afirmar que a força de trabalho pode ser trocada por bens ou dinheiro.

Marx (1998, p. 22-23) refere-se à troca como " preferência à sua aplicação, não exclusiva do capitalismo e que se caracteriza por sistema de produção generalizada de bens em que a força de trabalho pode ser comprada e vendida."

A industrialização da agricultura, referente a terra e sementes, é um fator essencial à produção de transgênicos no Brasil. A mercantilização da cadeia de produção agrícola firmada a empresas transnacionais concentra o capital dos meios de produção.

O Brasil por ser um grande agroexportador incorporou em suas práticas agrícolas a inovação da biotecnologia com o aumento das áreas de cultivos transgênicos de soja e milho em larga escala, fruto de um capitalismo agrícola global, ficando aquém o produto do trabalho humano em consonância com a natureza

Christoffoli (2009, p.83) define esse capital agrícola como "uma nova forma de domínio sobre a natureza e, na sequência, obtém sucesso em estabelecer a superestrutura jurídica que legitimará essa nova etapa de dominação sobre o trabalho e a natureza."

Ao mesmo tempo em que atende aos interesses econômicos, há uma falta de informação e ocultamento dos riscos associados aos produtos transgênicos, assim como em relação ao uso de agrotóxicos e a degradação da natureza em sua biodiversidade.

Na economia do mercado capitalista a interação entre ser humano e natureza tende a ser eliminada e reduzida à relação de dinheiro, isto é, à pressão do mercado por um constante aumento da produção de mercadorias, que domina a ordem social em prejuízo do ser humano e da natureza (ANDRIOLI, 2014).

O homem com sua própria ganância destruindo a vida na terra numa ação de poder com meros fins lucrativos, no intuito de progredir, tornando-se refém de uma sociedade alienada ao sistema capitalista. 


\section{As plantas Transgênicas no contexto escolar}

A proposta de trabalhar as plantas transgênicas surgiu da necessidade de esclarecer uma questão levantada em aula por uma aluna do oitavo ano da E.M.E.F.SILVINA GONÇALVES, referente à plantação de soja próxima a escola, quanto à aplicação de grande quantidade de inseticidas.

Para inicío do trabalho, a professora perguntou aos alunos se sabiam o que são plantas transgênicas. E, teve como resposta, um "NÃO" quase unânime.

Com vistas a essa resposta, a professora procurou esclarecer a questão de forma bem clara, trazendo como informação, dois vídeos que abordavam os transgênicos: JC Debate alimentos transgênicos 26/05/2015 www.youtube.com e Especial - Transgênicos www.youtube.com.

Esses vídeos, além de explicar que transgênico é uma modificação genética de um organismo, no caso da planta. Enfoca as vantagens e desvantagens do cultivo das plantas transgênicas e o risco à saúde humana com o uso dos produtos transgênicos, deixando a certeza de que o melhor esclarecimento é a informação.

Pois vivemos numa sociedade consumista e, cabe a cada indivíduo a escolha dos produtos utilizados diariamente para sua alimentação.

Os alunos assistiram aos vídeos e após organizaram-se em grupos de estudos com objetivo de realizar uma pesquisa em casa ou com familiares, vizinhos ou agricultores locais a fim de saber a forma como cultivam suas plantas. Como escolhem as sementes para o plantio da terra? O levam em consideração, o resultado da produção ou qualidade da semente utilizada? Também pesquisaram em casa o consumo cotidiano de produtos transgênicos.

A manipulação científica do patrimônio genético começou a ser desenvolvida há mais de trinta anos, possibilitando as modificações genéticas nos organismos vivos, trazendo evolução na área da agricultura.

Além do melhoramento genético para uma produção em grande escala, a utilização dos transgênicos têm também outros objetivos como diminuir os custos de produção (plantas resistentes a pragas, doenças ou herbicidas) ou aumentar a qualidade nutricional do produto (melhorando sua aparência, conteùdo nutricional,etc.)

Assuntos polêmicos relacionados a biotecnologia, passaram a ser discutidos na escola, mas o aluno em geral não tem um posicionamento considerável sobre a transgenia. 
Por tratar-se de um assunto frequente nas mídias e que gera muita discussão, o professor precisa estimular o diálogo, sendo um mediador da conversa. Fazendo o aluno refletir que o estudo das ciências produz conhecimento com argumentação na sua formação cidadã.

\section{Transgenia: Solução ou Ameaça à Vida?}

Diante das questões levantadas em sala de aula anteriormente, os alunos relataram a pesquisa feita em casa. Todos os alunos identificaram a utilização de produtos transgênicos na alimentação, no caso comum entre eles, o óleo de soja. Ressaltaram ainda, que lhes chamou atenção o símbolo do transgênico - T na embalagem do produto.

Outra questão destacada por todos os familiares dos alunos é o plantio de sementes transgênicas por serem mais resistentes às pragas das lavouras e uma maior produção de alimentos (milho e soja) produtos cultivados no município.

Após esta explanação, os alunos, escolheram um representante de cada grupo para expor suas ideias para os demais alunos, com relação a transgenia.

Todos os grupos constataram a importância da produção de sementes transgênicas. Alguns até destacaram o depoimento dos pais, onde diziam que "o lucro é bem maior", "hoje em dia é impossível pensar como antigamente, numa produção à deriva de pragas e doenças”.

Entretanto, reconhecem os problemas ambientais, os riscos à saúde humana e os impactos socioeconômicos trazidos pelos transgênicos. Houve discussão acerca do consumo dos alimentos transgênicos, porém a maioria dos alunos desta turma, assim como os pais destes, acreditam ser os transgênicos com todos os prós e contras, uma solução para a falta de alimentos da população, como também, um avanço na agricultura no sentido de gerar renda para os sojicultores da localidade.

E que, no plantio, visam o lucro da colheita para sustentar a família e entre uma ameaça de prejuízo e a certeza da produção em larga escala, preferem correr o risco do que não produzirem o suficiente para pagar ao Banco o financiamento da lavoura.

Foi colocado também pelos alunos que os pais não se preocupam na escolha dos alimentos, se estes são ou não transgênicos, não importa na hora da compra do produto. E, que eles próprios, muitas vezes buscam a marca ao invés de analisar a composição do produto. 
Constatado por todos mais uma vez que, o assunto produção de transgênicos, é defendido do ponto de vista de quem produz, ou seja, quem depende da produção destes, jamais irá assumir os problemas que eles ocasionam aos seres vivos.

Figura 1: Alunos do oitavo ano da Escola de Ensino Fundamental Municipal Silvina Gonçalves do município de Arroio Grande.

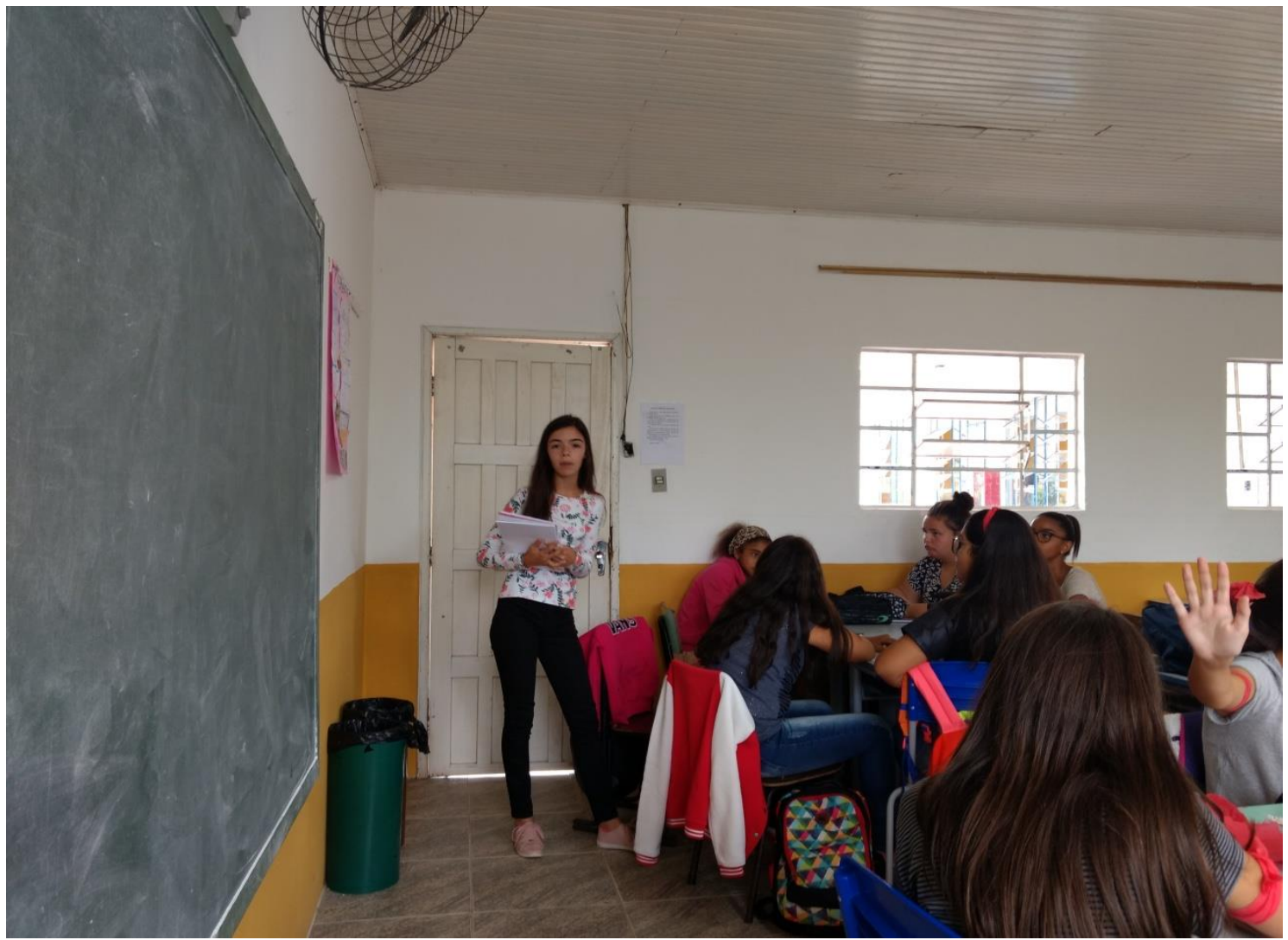

Fonte: Alunos da E.M.E.F.SILVINA GONÇALVES apresentando seus argumentos, pareceres e ideias com relação as plantas transgênicas e produção de alimentos, no relato de experiência pedagógica realizada com a turma de oitavo ano.

Defensores da biotecnologia agrícola argumentam que as culturas produzidas através de técnicas com modificações genéticas, como “ a biotecnologia pode[m] trazer muitos benefícios como o aumento da resistência das plantas às pragas e doenças, com consequente redução do uso de defensivos agrícolas, além da melhoria da tolerância a diferentes formas de estresse, como a seca, encharcamento e salinidade do solo" (RECH, 2014, p.55).

Definem ainda, que o mecanismo que transforma a ciência em um instrumento de dominação atua na expansão dessas culturas pelo financiamento de empresas públicas 
(Empresa Brasileira de Pesquisa Agropecuária - Embrapa) e privadas ( Monsanto, Syngenta, Bayer, Dupont, Dow Agroscience e outras) com investimentos em pesquisa.

Trata-se de uma nova concepção de trabalho, promovida com incentivo da União e com parceria da iniciativa privada, numa forma de alicerçar a experiência dos especialistas de mercado a fim de trazer segurança alimentar:

A Embrapa Soja atua em pesquisa com soja transgênica desde de 1997, quando em parceria com a iniciativa privada passou a incorporar às suas cultivares o gene de tolerância ao herbicida glifosato. [...] Para ter acesso à tecnologia, a Embrapa firmou contrato de pesquisa para incorporar o gene às suas cultivares com a Empresa Monsanto. Atualmente, a Embrapa mantém contratos de pesquisas similares com a Basf e outras empresas. (EMBRAPA, 2015).

Fundamentando-se assim, o relato dos pais dos alunos, que defendem a transgenia como uma solução para a agricultura brasileira referente a falta de alimentos para a população.

O Brasil, ocupa o segundo lugar em área de OGM plantada, perdendo apenas para os Estados Unidos da América, o que representa uma liderança global na área de OGM notadamente na safra de soja, algodão e milho tolerantes a herbicidas e resistentes a insetos (MATTÊ et al, 2014, p.116)

Os normativos sobre os OGM, no Brasil adotam o prncípio da precaução, prevenindo-se de uma situação de perigo com uma margem de segurança, ou seja, não sabendo ao certo os efeitos produzidos pela modificação genética.

Na legislação está o decreto $n^{\circ}$ 4.074/2002 (BRASIL, 2002) que complementa a Lei nº 7. 802/1989 (BRASIL, 1989) de agrotóxicos e afins em relação aos biopesticidas, incluindo a análise e o monitoramento dos OGM de ação biopesticida, cuja responsabilidade cabe à Agência Nacional de Vigilância Sanitária (Anvisa) e do Meio Ambiente (MMA).

A Lei $n^{o} 11.105 / 2005$ (BRASIL, 2005) complementa a competência da Coordenação-Geral da Comissão Técnica Nacional de Biossegurança (CTNBio) vinculada ao Ministério da Ciência, Tecnologia e Inovação (MCTI) em prestar apoio ao Governo Federal na formulação de Política Nacional de Biossegurança relativo aos OGM com normas de segurança e pareceres técnicos referentes à proteção da saúde humana, dos organismos vivos e do meio ambiente em atividades que envolvam experimentação, manipulação, consumo.

Entretanto, praticamente em todos os processos que levaram à liberação comercial de plantas transgênicas no Brasil, os estudos de biossegurança foram insuficientes por não avaliar todas as substâncias e características envolvidas. 
Existem ainda, muitos outros questionamentos relacionados com a falta de biossegurança na utilização e na produção de plantas transgênicas, como: 1) os impactos na saúde humana: agravos não esperados (alergias, toxidez, intolerância, entre outros): a presença de genes de resistência a antibióticos ( geração de novas raças de patógenos, rápida disseminação dos genes de resistência a antibióticos). Além destes, estudos comprovados cientificamente alertam para o perigo do uso de glifosato na produção de transgênicos, por ser altamente "cancerígeno"; 2) outros impactos: a criação de novas pragas e plantas daninhas; o aumento das pragas já existentes por meio da recombinação; a produção de substâncias que podem ser tóxicas a organismos não alvos; a contaminação de espécies nativas; o efeito adverso nos processos ecológicos; o aumento no uso de herbicidas com efeitos nocivos sobre a saúde humana, a fauna e a flora, comprometendo a qualidade da água, do solo e do ar.

Deste modo, a produção agrícola baseada na tecnologia de DNA recombinante, a transgenia, implica na mobilização de forças sociais trazendo uma nova maneira de se relacionar com a natureza. A ciência e a tecnologia aplicadas aos processos produtivos agrícolas são marcadas pelo acesso desigual aos meios de produção, ou seja, ocorre uma divisão específica de trabalho e o acumulo de capital.

Convém destacar que, as plantas transgênicas não atendem às necessidades da agricultura familiar, deixando os pequenos agricultores dependentes do uso de agrotóxicos, causando-lhes endividamento e ampliando a concentração dos latifúndios monocultores. Ressaltando também, a venda de sementes transgênicas vinculada à venda dos agrotóxicos, produzidas geralmente pela mesma empresa que tem um enorme poder sobre a economia, a política e o Estado. Estas sementes (transgênicas) são propriedades (patentes) de empresas transnacionais que articulam a mercantilização de um sistema capitalista, onde o agricultor paga royalties pelo invento, que são os genes modificados, e não pela semente.

Observa-se assim, uma falsa premissa com relação as plantas transgênicas, onde as alternativas sustentáveis de produção agrícolas são desconsideradas afetando a soberania alimentar, constituída durante milhares de anos, mediante a diversidade cultural dos povos.

Ocasionando assim a submissão da cultura alimentar ao discurso científico das empresas. Todavia, o sinal de alerta na produção transgênica é a vida com sua biodiversidade, complementando-se com a ampla diversidade cultural dos povos e isto constitui-se numa ameaça a toda espécie de vida na Terra.

\section{Considerações}


A transgenia tornou-se uma cultura de expansão do capitalismo ao desenvolver um modelo de produção agrícola que utiliza a natureza associada a expropriação dos meios de produção dos trabalhadores pela lucratividade. O aumento de lavouras transgênicas favorece todo um esquema de produção de sementes biotecnológicas desenvolvidas pelas empresas transnacionais.

Em suma, os agricultores, afirmam ter conhecimento das vantagens e desvantagens das plantas transgênicas para a produção de alimentos, mas consideram um progresso das forças produtivas com o avanço científico da biotecnologia.

Reconhecem também os prejuízos à saúde humana tanto na aplicação de herbicidas cada vez mais agressivos ao meio ambiente, como ao uso de alimentos transgênicos na alimentação diária. Contudo destacam que, para produzir mais alimentos, ou seja, uma produção em larga escala, é necessário adotar novas técnicas de plantio.

Afirmam ainda que, a transgenia gerou desenvolvimento econômico no município de Arroio Grande. O grande número de lavouras de soja contribuiu para uma arrecadação maior de impostos aos cofres públicos.

Desta forma, observa-se uma enorme contradição no avanço tecnológico da agricultura brasileira, sendo a desigualdade intrínseca ao processo social de produção científica, ficando os trabalhadores agrícola à mercê da mais-valia, onde a ciência não encontra limites para atuar sem controle sob a biodiversidade, a vida e a natureza em prol de um sistema capitalista sem visão sustentável.

Assim as alternativas sustentáveis de produção agrícola, tornam-se desnecessárias e insuficientes frente as alternativas de produção genético-químico- industrial.

Entretanto, o fator relevante e que merece maior atenção na produção transgênica, é a vida com sua biodiversidade, considerando também a diversidade cultural. Fatores estes que sofrem impactos negativos resultantes da ação humana aliada ao modo de produção determinante da sociedade.

\section{Referências}

ANDRIOLI, A. I. A atualidade de Marx para o debate ambiental. In: COLÓQUIO 
INTERNACIONAL MARX ENGELS, 5., 2007, São Paulo. Anais... São Paulo:

UNICAMP,2007Disponívelem:<http://www.unicamp.br/cemarx/anais_v_coloquio_arquivos/ arquivos /comunicacoes/gt2/sessao3/Antonio_Andrioli.pdf > Acesso em: 8 ago. 2014.

AUGUSTO, L.G.S. Transgênicos. In: CALDART, R.S.; PEREIRA, I.B.; ALENTEJANO, P.;FRIGOTTO, G. (Org.). Dicionário da Educação de Campo. Rio de Janeiro: Expressão Popular, 2012.

BRASIL. Lei n. ${ }^{\circ}$ 11.105, 24 de março de 2005. Diário Oficial [da] República Federativa do Brasil,Poder Executivo, Brasília, DF, 28 mar. 2005.

Seção1Disponívelem:<http://www.planalto.gov.br/ccivil_03/_ato2004/2006/2005/lei/111105. htm> Acesso em: 2 dez. 2014.

. Lei n. ${ }^{\circ} 7.802$, de 11 de julho de 1989. Diário Oficial [da] República Federativa do Brasil,Poder Executivo, Brasília, DF, 12 jul. 1989. Seção 1.Disponívelem:<http:// www.planalto.gov.br/ccivil_03/leis/17802.htm> Acesso em: 5 mar. 2015.

. Decreto n. ${ }^{\circ}$ 4.074, de 4 de janeiro de 2002. Diário Oficial [da] República Federativa do Brasil.Poder Executivo, Brasília, DF, 8 jan. 2002. Seção 1

Disponível em <http://www.planalto.gov.br/ccivil_03/decreto/2002/d4074.htm> Acesso em: 5 mar. 2015.

CHRISTOFFOLI, P. I. O processo produtivo capitalista na agricultura e a introdução dos organismos geneticamente modificados: o caso da cultura da Soja Roundup Ready (RR) no Brasil. 2009. Tese(Doutorado) - Centro de Desenvolvimento Sustentável. Universidade Brasília. Brasília, 2009.

EMBRAPA. Soja transgênica. Brasília: Embrapa, [200-]. Disponível em:<https://www.embrapa.br/web/portal/soja/cultivos/soja1/soja-transgenica> Acesso em: 1 . abr. 2015.

ESPECIAL. Transgênicos. Disponível em: HTTPS://www.youtube.com/watch?v=3Vox1B55t78 Acesso em: 26. Mar. 2018.

JC Debate alimentos transgênicos. Disponível em: <

HTTPS://www.youtube.com/watch?v=AlahJ3LEdB8. Acesso em: 26. Mar. 2018.

MARX, K. O Capital: crítica da economia política. 7. ed. Rio de Janeiro: Civilização

MATTÉ, G. R. et al. Regulação de Organismos Geneticamente Modificados de Uso Agrícola No Brasil e sua Relação com os Modelos Normativos Europeu e Stadunidense. Revista do Direito Sanitário, São Paulo, v. 14, n. 3, p. 112-131, nov. 2013/ fev. 2014. Disponível em: <http://www.revistas.usp.br/rdisan/article/view/79671/83672 >. Acesso em: 5 jan. 2015

RECH, E. Biotecnologia: aliada da ciência no combate à fome e na prevenção e erradicação de doenças. Revista USP, [São Paulo], n. 64, p. 122-131, fev. 2005. Disponível em: <http://www.revistas.usp.br/revusp/article/view/13395/15213> Acesso em: 6 nov. 2014. 